Supporting Information for

\title{
Interconversion of Triply Periodic Constant Mean Curvature Surface Structures: From Double Diamond to Single Gyroid
}

\author{
Xin Cao, ${ }^{\dagger}$ Dongpo Xu, ${ }^{\dagger}$ Yuan Yao, ${ }^{\dagger}$ Lu Han,${ }^{*, \dagger}$ Osamu Terasaki ${ }^{\ddagger, \&}$ \\ and Shunai Che*,† \\ 'School of Chemistry and Chemical Engineering, State Key Laboratory of Metal Matrix Composites, \\ Shanghai Jiao Tong University, 800 Dongchuan Road, Shanghai, 200240, China \\ ${ }^{\ddagger}$ Department of Materials \& Environmental Chemistry, EXSELENT Stockholm University, Stockholm, \\ Sweden \\ ${ }^{\S}$ Graduate School of EEWS, KAIST Daejeon, Republic of Korea
}

Email: chesa@sjtu.edu.cn, luhan@sjtu.edu.cn 


\section{Characterizsation of the polymer.}

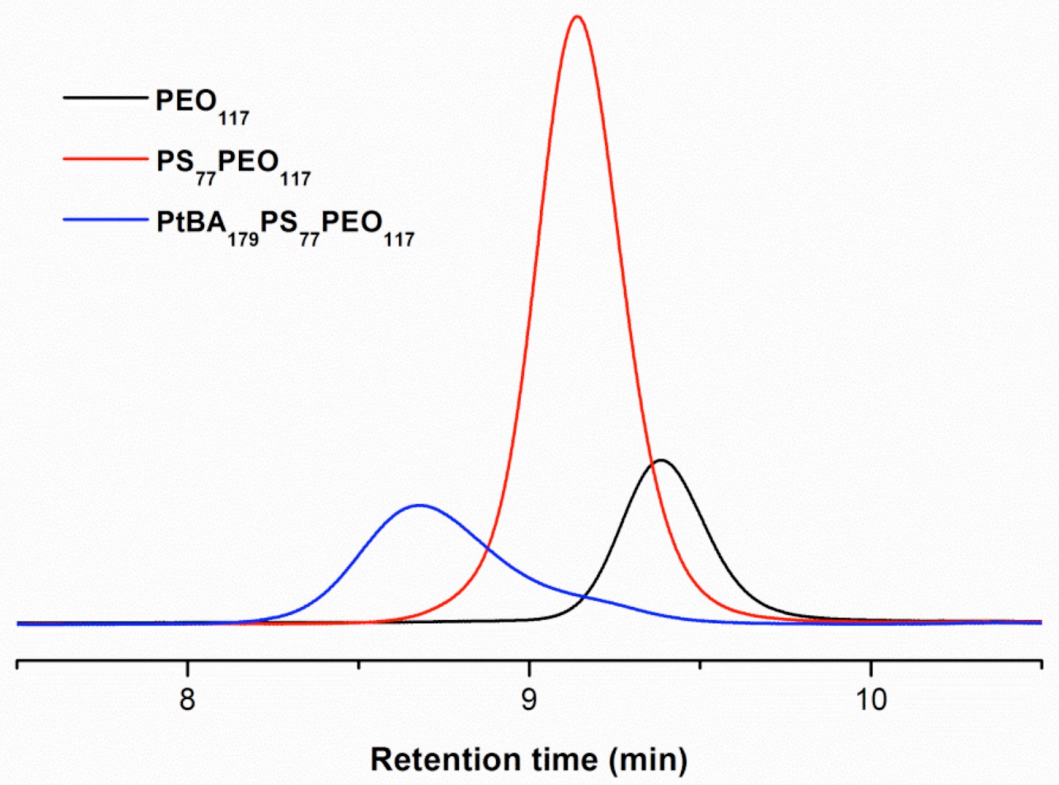

Figure S1. Gel permeation chromatograms of the polymers.

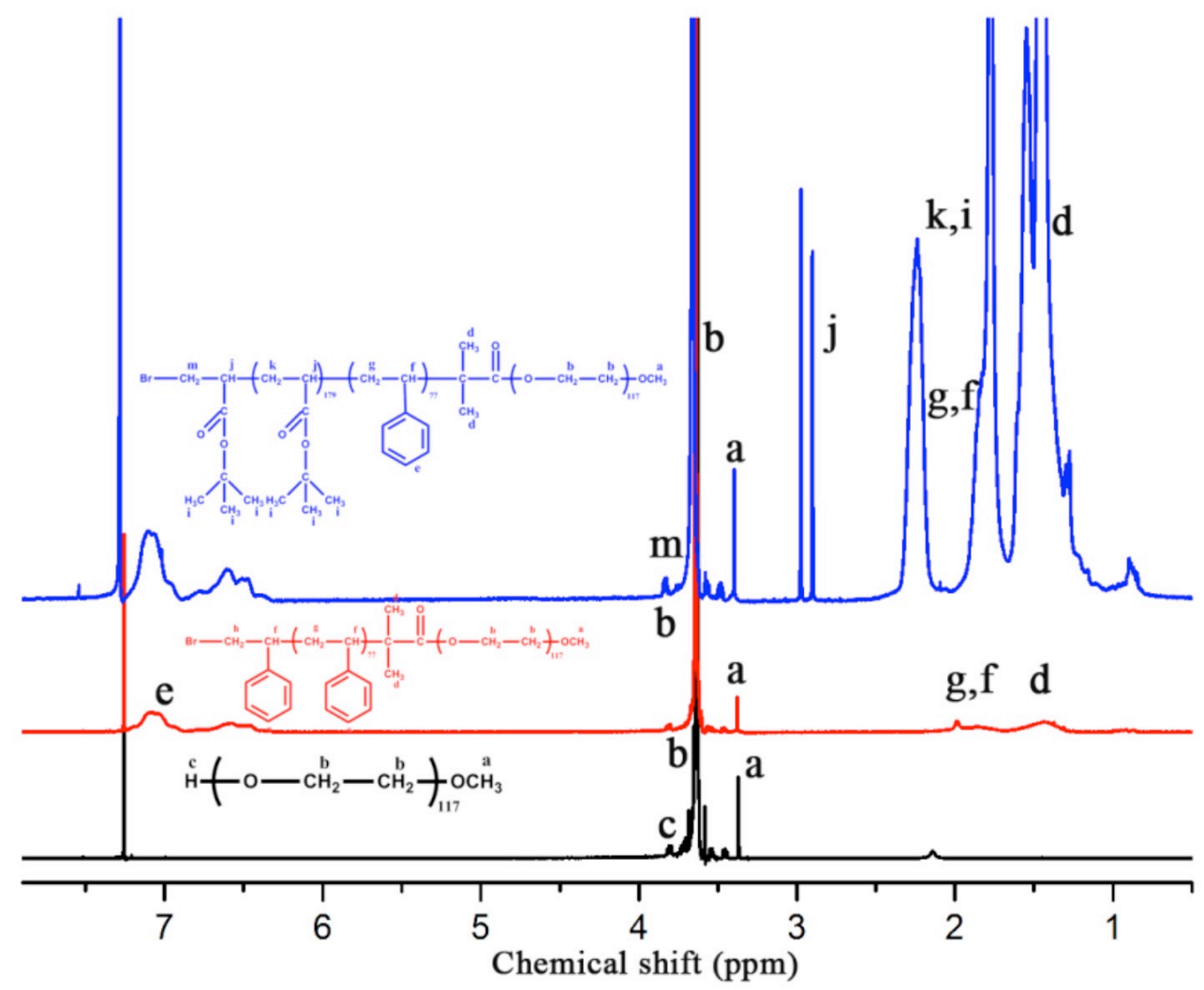

Figure S2. ${ }^{1}$ H NMR spectra of the polymers. 
Table S1. The number-averaged molecular weight, weight fraction and volume fraction of different blocks.

\begin{tabular}{ccccc}
\hline Component & $\mathrm{Mn}(\mathrm{kg} / \mathrm{mol})$ & $\mathrm{Wt} \%$ & Vol\% & PDI \\
\hline ASO & 36.1 & - & - & 1.386 \\
PtBA & 23.0 & $63.7 \%$ & $63.6 \%$ & - \\
PS & 8.1 & $22.4 \%$ & $22.9 \%$ & - \\
PEO & 5.0 & $13.9 \%$ & $13.6 \%$ & - \\
\hline
\end{tabular}

\section{The Estimation of $X N$ values}

The Flory-Huggins interaction parameters ${ }^{[1]}$ for terpolymer are calculated as approximately $\chi_{\mathrm{AS}} N$ $=10.6, \chi_{\mathrm{SO}} N=51.7$ and $\chi_{\mathrm{AO}} N=109.1$ by

$$
\begin{gathered}
\delta^{2}=\delta_{d}{ }^{2}+\delta_{p}{ }^{2}+\delta_{h}{ }^{2} \\
\chi N=\sum N \times V_{\text {ref }}\left(\delta_{1}-\delta_{2}\right)^{2} / R T
\end{gathered}
$$

where $V_{\text {ref }}$ is the segment reference volume $\left(100 \mathrm{~cm}^{3} / \mathrm{mol}\right)$, and $\delta_{\mathrm{i}}$ is the Hildebrand solubility parameter for polymer i $\left(\delta_{\mathrm{A}}=18.5\left(\mathrm{~J} / \mathrm{cm}^{3}\right)^{1 / 2}, \delta_{\mathrm{S}}=19.3\left(\mathrm{~J} / \mathrm{cm}^{3}\right)^{1 / 2}\right.$, and $\left.\delta_{\mathrm{O}}=21.2\left(\mathrm{~J} / \mathrm{cm}^{3}\right)^{1 / 2}\right)($ Table S2 and S3). The relationship $\chi_{\mathrm{AO}} N \gg>\chi_{\mathrm{SO}} N \gg>\chi_{\mathrm{AS}} N$ tends to form strong microphase separation between the PEO and PS/PtBA blocks while no obvious microphase separation between PS and PtBA blocks occurs, behaving like an AB block copolymer. The THF is the common solvent owing to the similar solubility parameters of THF $\left(\delta=18.6\left[\mathrm{~J} / \mathrm{cm}^{3}\right]^{1 / 2}\right)$, whereas water is the selective solvent $\left(\delta=23.4\left[\mathrm{~J} / \mathrm{cm}^{3}\right]^{1 / 2}\right)^{[2]}$. The silicate species would be hydrolysed and condensed in the $\mathrm{H}_{2} \mathrm{O}$ rich phase through the co-interaction of hydrogen bonding between ethylene oxide and silanol and the electrostatic interaction between $\mathrm{EO}_{\mathrm{m}-\mathrm{y}}\left[(\mathrm{EO}) \cdot \mathrm{H}_{3} \mathrm{O}^{+}\right] \mathrm{y}$ and $\left[\mathrm{yCl}^{-} \cdot \mathrm{Si}^{-} \mathrm{OH}^{2+}\right]^{[3]}$. The final silica scaffold was obtained through evaporation of both THF and water with the simultaneous hydrolysation and condensation of TEOS, and the template molecules were removed by calcination (Figure S3). 
Table S2. The solubility parameters of different blocks

\begin{tabular}{ccccc}
\hline Block & $\delta_{\mathrm{d}}\left(\mathrm{J} / \mathrm{cm}^{3}\right)^{1 / 2}$ & $\delta \mathrm{p}\left(\mathrm{J} / \mathrm{cm}^{3}\right)^{1 / 2}$ & $\delta \mathrm{h}\left(\mathrm{J} / \mathrm{cm}^{3}\right)^{1 / 2}$ & $\delta\left(\mathrm{J} / \mathrm{cm}^{3}\right)^{1 / 2}$ \\
\hline PtBA & 14.366 & 8.157 & 8.342 & 18.507 \\
PS & 16.723 & 8.253 & 5.149 & 19.346 \\
PEO & 16.742 & 10.137 & 8.142 & 21.200 \\
\hline
\end{tabular}

Table S3. The Flory-Huggins interaction parameters between blocks.

\begin{tabular}{cccc}
\hline & $\mathrm{A}^{-}$ & $\mathrm{S}^{-}$ & $\mathrm{O}^{-}$ \\
\hline $\mathrm{A}$ & & 10.6 & 109.1 \\
$\mathrm{~S}$ & 10.6 & & 51.7 \\
$\mathrm{O}$ & 109.1 & 51.7 & \\
\hline
\end{tabular}




\section{Formation of the silica scaffold}

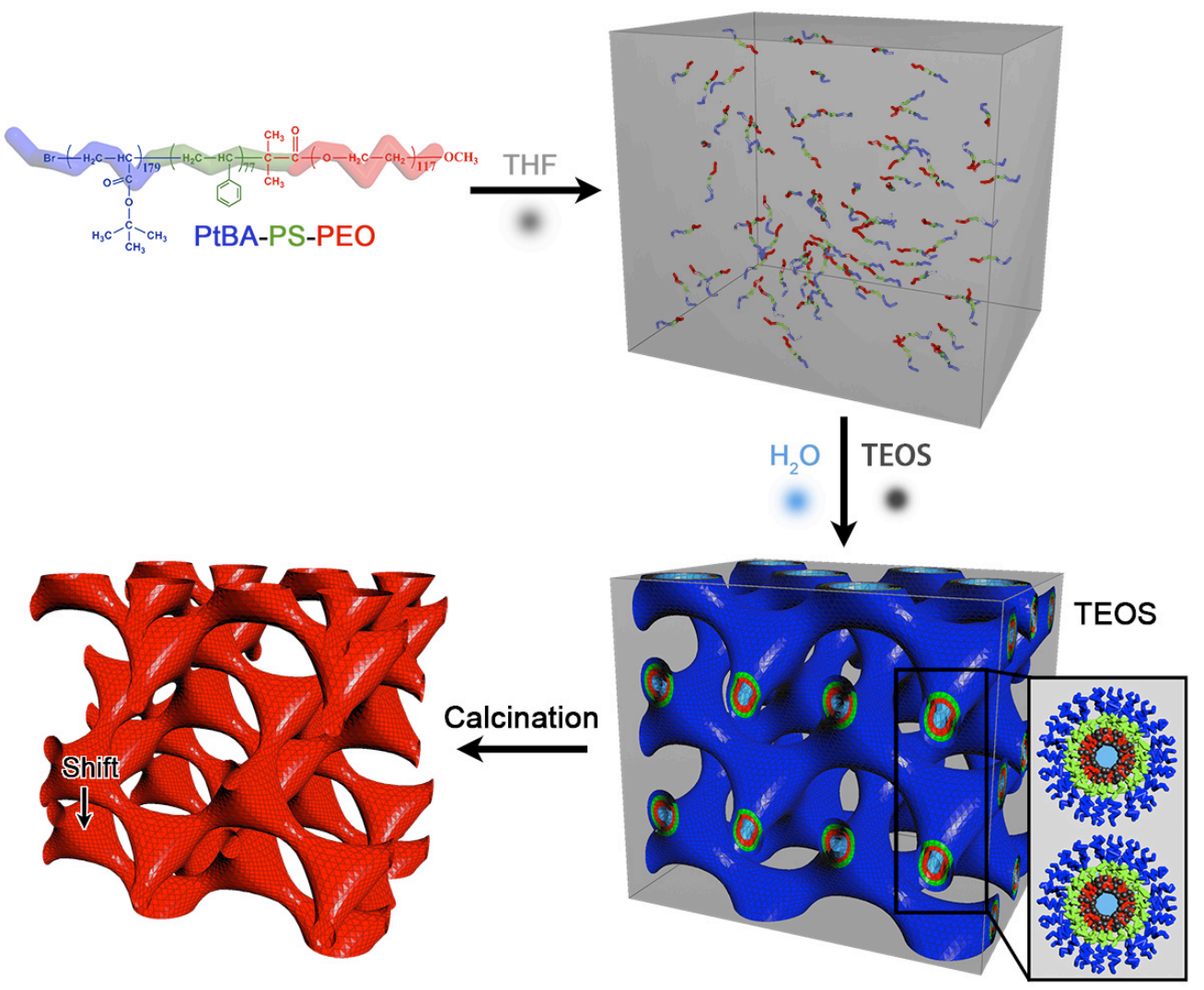

Figure S3. Representation of the formation of the material. The double diamond structure is shown as an example and the formation of the single gyroid is shown in Scheme 1 in the main text. The uniform polymer solution can be formed in the common solvent THF because of the similar solubility parameters of the terpolymer PtBA, PS, PEO, and THF. With the addition of the selective solvent water and the silica source TEOS, the multilayer core-shell bicontinuous double-diamond structure is formed because of the microphase separation. The continuous THF-rich core and waterrich phase are formed in the hydrophobic and hydrophilic regions, respectively, and the silica species are simultaneously condensed in the PEO-layer of the hydrophobic-hydrophilic interface to form a silica wall, which leads to the formation of the hollow double-diamond structure. When the THF solvent is evaporated from the hydrophobic region, the double-diamond frameworks lose the mutual support and adhere to each other to form a tetragonal structure. After calcination, the template is removed and the adhered hollow double-diamond structure is formed. 


\section{3D reconstruction of the structure}

The three-dimensional (3D) electrostatic potential map of the single gyroid structure is obtained by electron crystallography reconstruction to elucidate the structural details. The amplitudes and phases (with amplitudes $>0.5 \%$ of the largest amplitude for each direction) were extracted from the Fourier transforms of the TEM images along the three main directions using the crystallographic image-processing software CRISP. ${ }^{[4]}$ From the averaged TEM images, plane groups of $p 4 m m$, $p 2 m m$ and $p 3 m 1$ were assigned to the [100], [110] and [111] directions, respectively. The structure factors of reflections from different projections were merged into a 3D dataset by adjusting the common origin and normalized by scaling the amplitudes with the common reflections. The origin of each projection (shown in yellow in Figure 3) was moved to the common origin (shown in blue in Figure 3) of the unit cell. The contrast transfer function was corrected by a Wiener filter to avoid a zero division. ${ }^{[5]}$ Fifty two unique reflection was calculated to generate the $3 \mathrm{D}$ electrostatic potential map $\varphi(\mathrm{x}, \mathrm{y}, \mathrm{z})$ by employing the software application VESTA (Table S4). ${ }^{[6]}$ A threshold for the isosurface was determined from the TEM images because the boundary of the silica wall could be directly observed. 
Table S4. Crystal structure factors (amplitudes and phases) extracted from TEM images of the single gyroid structure.

\begin{tabular}{ccccc|ccccc}
\hline $\mathrm{h}$ & $\mathrm{k}$ & $\mathrm{l}$ & Amplitude & Phase & $\mathrm{h}$ & $\mathrm{k}$ & $\mathrm{l}$ & Amplitude & Phase \\
\hline 0 & 1 & 1 & 10000 & 90 & 0 & 0 & 8 & 37 & 180 \\
2 & 2 & 2 & 2459 & 90 & 0 & 2 & 8 & 33 & 0 \\
1 & 2 & 3 & 1484 & 108 & 2 & 5 & 7 & 28 & 168 \\
0 & 2 & 4 & 1012 & 180 & 0 & 6 & 6 & 28 & 0 \\
0 & 1 & 3 & 1679 & 90 & 3 & 4 & 7 & 26 & 116 \\
0 & 0 & 4 & 1075 & 0 & 2 & 2 & 8 & 26 & 0 \\
2 & 3 & 3 & 747 & 180 & 2 & 4 & 4 & 49 & 90 \\
1 & 1 & 2 & 1351 & 180 & 2 & 2 & 6 & 34 & 270 \\
0 & 2 & 2 & 1133 & 180 & 2 & 5 & 5 & 27 & 180 \\
2 & 2 & 4 & 351 & 180 & 0 & 7 & 7 & 14 & 90 \\
0 & 3 & 3 & 452 & 90 & 0 & 5 & 5 & 28 & 270 \\
1 & 3 & 4 & 205 & 196 & 1 & 1 & 8 & 19 & 90 \\
1 & 1 & 4 & 266 & 270 & 1 & 6 & 7 & 14 & 224 \\
2 & 3 & 5 & 104 & 114 & 0 & 1 & 7 & 24 & 90 \\
0 & 1 & 5 & 144 & 270 & 1 & 5 & 6 & 19 & 271 \\
1 & 4 & 5 & 84 & 153 & 6 & 6 & 6 & 10 & 270 \\
0 & 3 & 5 & 99 & 270 & 0 & 5 & 9 & 10 & 270 \\
1 & 1 & 6 & 81 & 0 & 1 & 7 & 8 & 8 & 324 \\
5 & 5 & 6 & 36 & 180 & 0 & 2 & 10 & 9 & 180 \\
0 & 2 & 6 & 75 & 0 & 0 & 3 & 9 & 10 & 90 \\
4 & 4 & 4 & 61 & 180 & 1 & 1 & 10 & 9 & 709 \\
0 & 4 & 4 & 89 & 50 & 0 & 8 & 8 & 7 & 0 \\
0 & 4 & 6 & 55 & 0 & 6 & 8 & 8 & 7 \\
4 & 6 & 6 & 31 & 40 & 2 & 6 & 6 & 10 & 90 \\
4 & 5 & 5 & 40 & 50 & 9 & 90 \\
\hline
\end{tabular}




\section{References}

[1] B. A. Miller-Chou, J. L. Koenig, A Review of Polymer Dissolution. Prog. Polym. Sci. 2003, $28,1223-1270$.

[2] C. M. Hansen, Hansen Solubility Parameters: A User's Handbook, CRC Press, 2012.

[3] D. Zhao, Q. Huo, J. Feng, B. F. Chmelka, G. D. Stucky, Nonionic Triblock and Star Diblock Copolymer and Oligomeric Surfactant Syntheses of Highly Ordered, Hydrothermally Stable, Mesoporous Silica Structures, J. Am. Chem. Soc. 1998, 120, 6024-6036.

[4] S. Hovmöller, CRISP: Crystallographic Image Processing on a Personal Computer, Ultramicroscopy 1992, 41, 121-135.

[5] O. Terasaki, T. Ohsuna, V. Alfredsson, J. O. Bovin, D. Watanabe, K. Tsuno, The Study of Zeolites by HVHREM. Ultramicroscopy 1991, 39, 238-246.

[6] K. Momma, F. Izumi, VESTA 3 for Three-dimensional Visualization of Crystal, Volumetric and Morphology Data. J. Appl. Crystallogr. 2011, 44, 1272-1276. 